\title{
Country performance during the Covid-19 pandemic: externalities, coordination, and the role of institutions
}

\author{
Santiago Lago-Peñas ${ }^{1}\left[\right.$ [ Jorge Martinez-Vazquez ${ }^{2}$ (1) $\cdot$ Agnese Sacchi $^{3}$ (1)
}

Received: 7 December 2020 / Accepted: 26 November 2021 / Published online: 10 December 2021

(c) The Author(s), under exclusive licence to Springer-Verlag GmbH Germany, part of Springer Nature 2021

\begin{abstract}
The Covid-19 pandemic is one of the most powerful examples of negative externalities in local communities, entire countries and across the globe, calling for the coordination of policies at all levels. We focus on the role played by institutions at the country level in fighting the spread of Covid-19 by making policy coordination more difficult or, on the contrary, more effective. Specifically, we consider the type of political regimes, political fragmentation, and decentralization settings, after controlling for several non-institutional factors. We assemble several data sources with the most recent available information on Covid-19 performance for up to 113 countries around the world. Our main results, which are robust to alternative specifications, show that having either democracies or autocracies does not represent a crucial issue for successfully addressing the pandemic. Most significantly, we find that countries with centralized political parties, which fundamentally allow for better coordination at the national level, perform significantly better than those with decentralized political parties. Although federal countries do appear to have had consistently greater difficulties than unitary countries, a finding that fits well with the role of coordination, overall, the role played by fiscal and administrative decentralization is not robust, but this latter is a result conditioned by the lack of data availability.
\end{abstract}

Keywords Covid-19 Policy coordination $\cdot$ Externalities $\cdot$ Decentralization . Democratic institutions · Political fractionalization

Agnese Sacchi

agnese.sacchi@uniurb.it

Santiago Lago-Peñas

slagop@uvigo.es

Jorge Martinez-Vazquez

jorgemartinez@gsu.edu

1 Governance and Economics Research Network (GEN), Universidade de Vigo, Vigo, Spain

2 International Center for Public Policy, Georgia State University, Atlanta, USA

3 Department of Economics, Society, Politics, University of Urbino, Via Saffi 42, 61029 Urbino, Italy 
"In a pandemic, the thing has to be about 'we' not 'I.'” (Dr. Krutika Kuppalli, Stateline 8 August 2020)

\section{Introduction}

The Covid-19 pandemic represents an unprecedented social and economic disruption in the modern history of the world. Its impact has been devastating with over 1 million deaths so far around the world and severe economic losses in many countries-some losing over one-fourth of their GDP in 2020. One of the most striking observations during these difficult times has been the extremely diverse performance across countries in containing the pandemic and the economic outcomes that have ensued.

Our main research question is devoted to explaining what might be behind those large differences in performance across countries. In doing that, we rely on the economic theory of (negative) externalities and how coordination at the highest level is needed to address or "internalize" those externalities. ${ }^{1}$ The Covid-19 pandemic is, indeed, one of the most powerful examples of negative externalities in local communities, entire countries and also across the globe, that one can possibly come up with.

During 2020, we have seen that local actions in Wuhan (China) did not only affect the city of Wuhan, but also the province of Hubei, the entire country of China, and the rest of the world. Fighting or addressing this powerful externality, as for any other type of negative externality, requires policy coordination such that agents are made to recognize or internalize in their decisions not only the self-costs and benefits of their actions, but also those imposed on the others.

Looking at single country experiences, intergovernmental coordination practices used in Germany, Denmark and Australia have received international attention for their success in controlling the first wave of Covid-19, by implementing nationwide policies and exerting a strong national leadership. On the other hand, as highlighted by Legido-Quigley et al. (2020), in other countries like Italy and Spain, the Covid19 crisis placed pressure on all building blocks of the health systems starting from their governance and the coordination between the national and regional authorities, since responsibility for health is devolved to many and very diverse territories. In large federations, like the United States, Brazil, India or Pakistan, many sub-national governments took actions, but those actions were not coordinated at the federal level (Dzau and Balatbat 2020).

Looking beyond single country situations, the World Health Organization (WHO) can be interpreted as a supranational institution in charge of coordinating this emergency (and many other health issues at the international level), by helping countries

\footnotetext{
1 In economic theory, externalities refer to the effects (negative or positive) that some actions by economic agents may have on third party groups without any compensation or payments for receiving those effects, and opening room for the market of incomplete contracts. In an intergovernmental framework, addressing negative externalities (e.g., related do pollution and climate change) generally require strong national-state-local coordination (Lin, 2010; Hankla et al., 2019).
} 
recognize the importance of their actions as affecting other citizens of the world. Likewise, we can interpret the actions and advise of supranational organizations, such as the European Union to their member countries, in the same fashion, that is as coordination policies addressing cross-country (negative) externalities within its geographical boundaries.

Of course, the advice and recommendations of the WHO and other supranational organization may affect the behavior and, ultimately, the public health performance of countries during the pandemic. However, our main hypothesis is that once one controls for "external" or predetermined circumstances for each country (e.g., previous experience with respiratory diseases such as SARS or MERS, external exposure via tourism flows, or different levels of urbanization proximity), the success or failure of such performance depends critically on their institutional setup. More specifically, on how the latter facilitates the coordination for the necessary preventive policies to face and contain the pandemic. Thus, our focus is on the type of institutions at the country level that may make it more difficult or, on the contrary, enhance policy coordination to fighting the spread of Covid-19. ${ }^{2}$

Three types of institutions affecting policy coordination are highlighted in our analysis: the political regime (whether countries are more/less democratic); the geographical political fragmentation (how integrated or centralized national political parties are); the fiscal and administrative decentralization (how policy decisions and spending authority are allocated among different levels of government). Even though democratic institutions are very desirable and have all kinds of beneficial effects, it is possible that in addressing this type of strong externality, the strict coordination facilitated by autocratic regimes may provide them with the upper hand to perform more effectively.

But within democratic regimes, the ability to coordinate policies is also affected by other institutional dimensions. In the case of political fractionalization, countries with centralized or integrated political parties are likely to be able to coordinate policies regarding issues with considerable externalities as in the case of the Covid-19 pandemic because of electoral incentives, discipline, and the structure of budgets ((Lago-Peñas and Lago-Peñas 2009; Hankla et al. 2019). Finally, in the case of policy decentralization, the sub-national assignment of responsibilities can have many advantages, including higher responsiveness to local needs and greater accountability (Uchimura and Jütting 2009; Channa and Faguet 2016). However, in the presence of large externalities, as in the case of such pandemic, higher levels of decentralization can make policy coordination much harder, leading to inefficient outcomes (as classically argued by Oates 1972). Finally, the whole institutional effectiveness may be mediated by other country's characteristics such as the extent of informality,

\footnotetext{
${ }^{2}$ Other alternative mechanisms may have been at play. For example, the presence of economies of scale can make centralized policy more effective, and that would reinforce the role of controlling externalities. There is also the possibility that sub-national governments may have tried early on to game the system by spending fewer resources hoping that the central government will take the lead and incur the required expenses instead.
} 
the level of human development, and so on, which need to be controlled for in the empirical analysis. The full list of control variables is discussed below.

To empirically test these hypotheses, we assembled several cross-country datasets with the most recent available information on Covid-19 performance for up to 113 countries around the world. Our main results, which are robust to several specifications and different variable definitions, show that having either democracies or autocracies does not represent a crucial issue in facing the pandemic. However, countries with centralized political parties perform better than those with decentralized political parties. Although federal countries do appear to have had consistently greater difficulties than unitary countries, a finding that fits well with the role of coordination, overall, the role played by fiscal and administrative decentralization is not robust.

The rest of the paper is organized as follows. In Sect. 2 we review the relevant literature. Section 3 describes the data and the empirical methodology. Section 4 presents and discusses the estimation results. Section 5 concludes.

\section{Literature review: how have governments coordinated their responses to Covid-19?}

Given the recentness and contingent nature of the process, there is not much published scientific evidence on how country governments coordinate responses to the emergency of Covid-19. But undoubtedly, national, and sub-national governments have adopted a wide range of policies and targeted actions to cope with this public health emergency and its economic impact (Hale et al. 2020).

In some cases, the effectiveness of sub-national actions to control the Covid-19 appeared to be undermined by the absence of a national policy (Iverson and Barbier 2020). Lacking national government effectiveness also restricted subnational governments capacity to react early to what was taking place elsewhere and to learn from the successes and mistakes of measures adopted in other places. In this context, even observing better local performances did not compensate for the failures in national government effectiveness.

At the same time, in countries where regional autonomy has been politically and fiscally important, the adoption of new national measures and laws to fight the pandemic have become controversial, especially when these new powers related to health services have been taken back by the central governments (Legido-Quigley et al. 2020). Additionally, there is evidence that in fighting the Covid-19 pandemic, national government effectiveness was far more important than regional government effectiveness in taming the virus, at least during the first wave: countries with better national government effectiveness were far more likely to have had lower levels of excess mortality in the first six months of 2020 (Rodríguez-Pose and Burlina 2021).

Some common trends can be observed across counties. The impact of Covid-19 on sub-national governments' spending consisted in higher costs for specific public services, such as social protection and assistance, cleaning, sanitation, and disinfection; the impact of Covid-19 has been described as "a heat-seeking missile speeding toward the most vulnerable in society" (Schellekens and Sourrouille 2020). 
However, strikingly, the mortality rate from Covid-19 remains highly concentrated in more developed and high-income countries, which are generally also characterized by an extensive presence of democratic institutions and well-structured intergovernmental systems. This would suggest that among the main lessons from the Covid-19 pandemic experience, one of the most relevant is represented by the need for better cooperation and coordination of efforts by policy-makers at the subnational and national levels (Snower 2020).

While the role of democratic institutions on economic development have been extensively studied by economists (e.g., de Haan et al. 1996; Acemoglu et al. 2014), little is known about the role of political regime in powering better coordination in the presence of very large externalities like those associated with the Covid-19. There is a literature in economics and political science arguing that the type of political decentralization institutions plays an important role in democratic decentralized countries (Hankla et al. 2019). Following the seminal contribution by Coase (1960), the idea is that the size of externalities may be mitigated in a decentralized system through voluntary intergovernmental coordination. An application of this argument is provided by Klibanoff and Morduch (1995) who show that, given the superiority of local information and respect for the autonomy of individual localities, there is an important interaction between size of the externality and the efficacy of coordination. Accordingly, efficient outcomes can only be achieved through coordination when external effects are relatively large. ${ }^{3}$ A similar result is presented by Dur and Roelfsema (2005) explaining that centralization of political decision-making often fails to produce the desired result of internalizing externalities since it yields in overspending in some policy domains, whereas too low spending persists in others.

On the other hand, it is argued that centralized political parties with power to nominate local candidates run and enforce national policy platforms are generally more effective-and have much more interest in-addressing (negative) externalities, than decentralized or non-integrated parties (Hankla et al. 2019). Put differently, centralized decision-making would completely resolve the externality problem provided that local governments delegate bargaining to agents who have the same preferences for public goods as themselves (see Besley and Coate 2003). Arguably, at the country level such delegation process could be more problematic as several negative (and positive) externalities might occur between countries, ranging from macroeconomic spillovers to environmental damage, also including either health or pandemic episodes. In this case, the only way for two countries to overcome this problem may be to give up real power to a higher authority by entering a federation or a union (Inman and Rubinfeld 1992; Ellingsen 1998).

The decentralization of expenditure responsibilities for health services around the world has been generally shown to yield positive outcomes on health indicators and metrics (Martinez-Vazquez et al. 2017). However, it is generally accepted among decentralization experts that for health issues with large externalities, like

\footnotetext{
${ }^{3}$ By contrast, the authors find that coordination cannot yield any improvement at all when external effects are relatively small, and this may help to explain why coordination is so seldom observed in practice.
} 
vaccinations or contagious infectious diseases, the assignment of responsibilities should be at the central level, but in practice country policies vary.

In an interesting and related study, González-Bustamante (2021) investigates the role of several dimensions of states' administrative capacity, including coordination, to manage the Covid-19 crisis but only for a sample of eight South American countries. Apart from the heterogeneity in the evolution of the epidemic, he finds that analytical capacity associated with the adequate evaluation of pressure on the health system are significant factors for the rapid implementation of governments' suppression strategies.

In summary, little has been written or known about how different institutional arrangements may help or hinder policy coordination and cooperation in the face of a pandemic like the world has been experiencing in 2020. Our paper contributes to fill that void in the literature.

\section{The empirical analysis}

\subsection{Model specification and methodology}

Our base econometric specification for the empirical testing is the following:

$$
\text { DEATHS }_{i}=\alpha+\beta \cdot \text { DISEASE }_{i}+\delta \cdot \text { SOCIOECONOMIC }_{i}+\gamma \cdot \text { INSTITUTIONS }_{i}+\varepsilon_{i}
$$

We run regressions with data for a large sample of countries (at maximum 113, as listed in the Appendix) including developed, developing and transition economies, and the variables are based on the most recent year available for each country. The selection of the sample is based on data availability. The full list of included countries is in the Appendix. ${ }^{4}$

Estimates with cross-section data are performed using Ordinary Least Squares (OLS). Heteroskedasticity was detected using the White test in some estimates. Standard errors are therefore replaced by robust Huber-White errors. Maximum Variance Inflation Factor (VIF) values for each estimate are reported to detect multicollinearity problems. Attending to reported scores, we discard serious concerns on this respect. The lack of data on the measure of decentralization $R A I$ for several countries explain the change in the number of observations across estimations.

\subsection{The dependent variable}

Our dependent variable (DEATHS) is the number of accumulated deaths due to the Covid-19 over population in millions reported up to three dates: September

\footnotetext{
${ }^{4}$ In the sample we exclude Peru because it is an extreme outlier which severely distorts the estimation results, based on the use of three complementary influence statistics (RStudent, DRResid and DFFITS). After the data were revised in 2021 by the WHO, Peru became by far the country with the worst death toll.
} 
30th, 2020; December 31st, 2020, and June 30th, 2021. Thereby, we can check for changes in the influence of the explanatory variables, as argued in previous sections. We discarded the use of Covid-19 reported cases because measurement errors are larger, especially in the first months of the pandemic. ${ }^{5}$

\subsection{The explanatory variables: political and fiscal institutions}

To test the role of political and fiscal institutions (INSTITUTIONS), we focus on three dimensions. First, we consider the extent of political rights, which accounts for how easily public authorities may impose restrictions on their population (POLITICAL RIGHTS). Specifically, the variable is measured on a 1-7 scale: 1 for the highest degree of freedom; and 7 for the lowest. Hence, higher (lower) values of POLITICAL RIGHTS indicate a political regime with less (more) democracy. The basic rationale is that the less democracy, the more restrictions can be easily imposed by public authorities. Accordingly, more public restrictions are likely to be associated with less accumulated deaths due to the Covid-19 over population. Therefore, we expect a negative association between POLITICAL RIGHTS and DEATHS. ${ }^{6}$

Second, the degree of the nationalization of party systems (PSNS) is employed to account for spatial fractionalization of politics in addressing the Covid-19 emergency. This variable measures the homogeneity of parties' vote shares across districts and the ability of central party institutions to control a national level policy agenda and nominations to electoral by subnational candidates. (Lago-Peñas and Lago-Peñas 2011; Hankla et al. 2019). This indicator goes from 0 to 1: the higher the score, the higher the nationalization of electoral politics. Hence, we expect a negative coefficient for PSNS on DEATHS.

Third, to capture the potential role played by policy decentralization, which is expected to contribute to coordination failure, we employ a set of three variables. Federal countries are identified using a dummy variable (FEDERAL). The advantage of this variable is its availability for all countries and its straightforwardness in relaying size and coordination challenges. We expect federal regimes to be positively associated with $D E A T H S$. In turn, we use the Regional Authority Index (RAI) provided by Hooghe et al. (2016), which is a precise measure of the influence of decentralization in public policies, including both the extent of self-rule over decentralized powers and the influence of regional governments on national choices. Unfortunately, this variable is available for only 80 countries. We expect a positive association between the RAI with DEATHS, because higher levels of fiscal and administrative decentralization are expected to hamper national policy coordination.

\footnotetext{
${ }^{5}$ In addition, we also explored relying upon the "excess mortality statistics" computed by several private and public institutions as an alternate dependent variable. However, these data are only available for a small number of countries, between 20 and 30, depending on the source.

${ }^{6}$ Results hold when we replace this variable by civil liberties also provided by the World Bank, or the quality of democracy by Hankla et al. (2019). Correlations among those three variables are very high.
} 


\subsection{The control variables}

The control variables are organized in two vectors. The vector DISEASE includes two variables: first, a dummy (IRD) to identify those countries previously shocked in recent times by other health viruses provoking infectious respiratory diseases (e.g., SARS, MERS or H7NP); we anticipate that those previous experiences would facilitate combating the Covid-19.

The vector SOCIOECONOMIC includes five variables: first, tourism flows received, which accounts for the potential easier and earlier exposure to the virus (TOURISM). Second, the country's per capita income (GDP): richer countries have more resources to deal with the virus and reduce mortality; however, richer countries may also be more exposed because of higher international travel. Third, the share of population over 64 because the severity of the disease increases with age (AGE65). Indeed, especially across European countries ageing as well as differences in ageing trends have represented a factor for excess mortality (e.g., Kashnitsky and Aburto 2020; Rodríguez-Pose and Burlina 2021). Fourth, we explore the potential role played by informality in the overall economy (INFORMAL) since a wide informal sector could moderate the role of formal institutions and adversely affect the government's ability to effectively coordinate policies against the pandemic. Last, we also include the share of urban population over total population (URBAN) to account for the fact that in higher population density settings, the contagion is easier. ${ }^{8}$

Table 1 reports the variable definitions and data sources, and Tables 2 and 3 shows the basic descriptive statistics for each variable used in the empirical analysis. In this case, we provide information for the full sample (113 countries) and the constrained sample due to availability data of variable $R A I$ ( 68 countries), and the three time points of the dependent variable mentioned above.

\footnotetext{
${ }^{7}$ In previous versions of this paper, we also included the average incidence of the Covid-19 pandemic in border countries using the same definition of the dependent variable. While this neighboring geographical exposure was statistically significant, the presence of endogeneity was detected by tests on residuals. The reverse causation is that the number of cases observed in border countries are also affected by the epidemiological situation of the country. While we tried to use lagged values to avoid the problem, the path dependence of accumulated cases makes this strategy invalid (Bellemare et al. 2017). We also tried several possible IVs based on the incidence of the flu and vaccinations in prior years but run into data availability issues. Hence, we decided to set aside this variable.

${ }^{8}$ This variable is highly correlated with population density and therefore we opted for using only one of two. In preliminary estimations, we included additional regressors. But they were discarded due high multicollinearity issue. In preliminary estimations we also included several indicators of quality of governance provided by the QoG Institute (https://www.gu.se/en/quality-government/qog-data). In particular, the ICRG indicator and the Government Effectiveness Estimate. However, their statistical significance was very low, and they were excluded from the final list of regressors.
} 


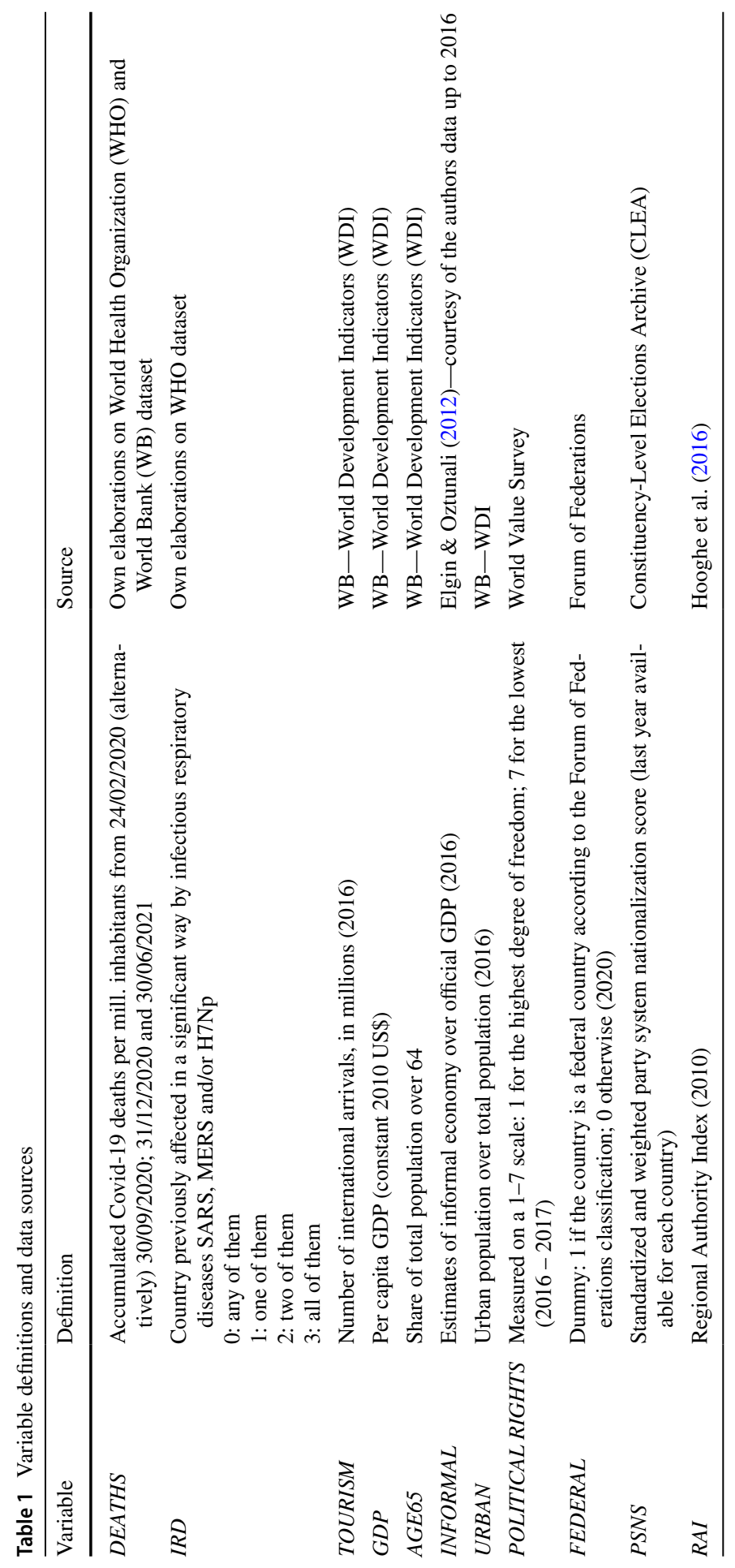


Table 2 Summary statistics (Full sample)

\begin{tabular}{lllllll}
\hline & Mean & Median & St. Dev & Minimum & Maximum & Observations \\
\hline Dependent variables & & & & & & \\
DEATHS (30 September 2020) & 148 & 54 & 209 & 0 & 886 & 113 \\
DEATHS (31 December 2020) & 373 & 211 & 418 & 0 & 1733 & 113 \\
DEATHS (30 June 2021) & 831 & 538 & 830 & 0 & 3056 & 113 \\
Control variables & & & & & & \\
IRD & 0.17 & 0.00 & 0.39 & 0.00 & 2.00 & 115 \\
TOURISM & 8.90 & 2.79 & 15.0 & 0.03 & 82.7 & 113 \\
GDP & 16,895 & 7,631 & 21,326 & 458 & 110,162 & 113 \\
AGE65 & 10.30 & 8.96 & 6.49 & 1.90 & 26.6 & 113 \\
INFORMAL & 0.29 & 0.28 & 0.12 & 0.08 & 0.62 & 113 \\
URBAN & 60.8 & 63.5 & 21.8 & 16.3 & 100 & 113 \\
Political \& fiscal institutions & & & & & & 113 \\
POLITICAL RIGHTS & 2.72 & 2.00 & 1.80 & 1.00 & 7.00 & 113 \\
FEDERAL & 0.17 & 0.00 & 0.38 & 0.00 & 1.00 & 113 \\
PSNS & 0.71 & 0.76 & 0.19 & 0.01 & 0.93 & \\
\hline
\end{tabular}

Table 3 Summary statistics (Constrained sample)

\begin{tabular}{lllllll}
\hline & Mean & Median & St. Dev & Minimum & Maximum & Observations \\
\hline Dependent variables & & & & & & \\
DEATHS (30 September 2020) & 217 & 115 & 238 & 1 & 886 & 68 \\
DEATHS (31 December 2020) & 545 & 443 & 433 & 1 & 1733 & 68 \\
DEATHS (30 June 2021) & 1182 & 1076 & 848 & 6 & 3056 & 68 \\
Control variables & & & & & & \\
IRD & 0.24 & 0.00 & 0.46 & 0.00 & 2.00 & 68 \\
TOURISM & 13.2 & 6.26 & 18.0 & 0.03 & 82.7 & 68 \\
GDP & 25,830 & 15,820 & 23,383 & 1,895 & 110,162 & 68 \\
AGE65 & 13.8 & 14.6 & 5.62 & 4.44 & 26.6 & 68 \\
INFORMAL & 0.25 & 0.25 & 0.11 & 0.08 & 0.59 & 68 \\
URBAN & 71.8 & 74.0 & 15.2 & 31.2 & 100 & 68 \\
Political \& fiscal institutions & & & & & & 68 \\
POLITICAL RIGHTS & 1.96 & 1.00 & 1.36 & 1.00 & 7.00 & 68 \\
PSNS & 0.75 & 0.81 & 0.15 & 0.34 & 0.93 & 68 \\
RAI & 10.6 & 8.60 & 10.0 & 0.00 & 37.0 & 68 \\
\hline
\end{tabular}

\section{Empirical results}

The estimation results are reported in Table 4. Columns [1a] and [2a] use data on deaths up to 30 September 2020; columns [1b] and [2b] report results with data until the end of 2020; and, last, columns [1c] and [2c] exploit information up to 30 June 2021. 
Table 4 Econometric results

\begin{tabular}{|c|c|c|c|c|c|c|}
\hline & [1a] & {$[1 \mathrm{~b}]$} & {$[1 \mathrm{c}]$} & [2a] & {$[2 \mathrm{~b}]$} & {$[2 \mathrm{c}]$} \\
\hline IRD & $\begin{array}{c}-102.7 \\
{[2.27]^{* *}}\end{array}$ & $\begin{array}{c}-169.0 \\
{[2.14]^{* *}}\end{array}$ & $\begin{array}{l}-278.5 \\
{[1.79]^{*}}\end{array}$ & $\begin{array}{l}-112.0 \\
(1.86)^{*}\end{array}$ & $\begin{array}{l}-232.7 \\
(2.18)^{* *}\end{array}$ & $\begin{array}{l}-444.1 \\
(1.95)^{*}\end{array}$ \\
\hline TOURISM & $\begin{array}{l}6.08 \\
{[5.98] * * *}\end{array}$ & $\begin{array}{l}6.02 \\
{[2.84] * * *}\end{array}$ & $\begin{array}{l}5.92 \\
{[1.29]}\end{array}$ & $\begin{array}{l}5.33 \\
(3.04) * * *\end{array}$ & $\begin{array}{l}5.55 \\
(1.96)^{* *}\end{array}$ & $\begin{array}{l}5.33 \\
(0.80)\end{array}$ \\
\hline GDP & $\begin{array}{l}-0.004 \\
{[0.42]}\end{array}$ & $\begin{array}{l}-0.004 \\
{[1.64]}\end{array}$ & $\begin{array}{l}-0.017 \\
{[3.16]^{* * *}}\end{array}$ & $\begin{array}{l}-0.001 \\
(0.56)\end{array}$ & $\begin{array}{l}-0.005 \\
(1.62)\end{array}$ & $\begin{array}{l}-0.019 \\
(3.28)^{* * *}\end{array}$ \\
\hline AGE65 & $\begin{array}{l}-5.23 \\
{[1.65]}\end{array}$ & $\begin{array}{l}28.4 \\
{[3.28] * * *}\end{array}$ & $\begin{array}{l}72.6 \\
{[4.12]^{* * *}}\end{array}$ & $\begin{array}{l}-11.4 \\
(2.20)^{* *}\end{array}$ & $\begin{array}{l}17.8 \\
(1.74)^{*}\end{array}$ & $\begin{array}{l}55.5 \\
(2.83)^{* * *}\end{array}$ \\
\hline INFORMAL & $\begin{array}{l}122.6 \\
{[0.49]}\end{array}$ & $\begin{array}{l}0.70 \\
{[0.002]}\end{array}$ & $\begin{array}{l}-252.3 \\
{[0.37]}\end{array}$ & $\begin{array}{l}345.0 \\
(0.98)\end{array}$ & $\begin{array}{l}-260.7 \\
(0.38)\end{array}$ & $\begin{array}{l}-952.6 \\
(0.72)\end{array}$ \\
\hline$U R B A N$ & $\begin{array}{l}4.17 \\
{[4.24] * * *}\end{array}$ & $\begin{array}{l}4.53 \\
{[2.78] * * *}\end{array}$ & $\begin{array}{l}11.5 \\
{[3.83]^{* * *}}\end{array}$ & $\begin{array}{l}4.55 \\
(2.61) * * *\end{array}$ & $\begin{array}{l}0.62 \\
(0.18)\end{array}$ & $\begin{array}{l}2.48 \\
(0.38)\end{array}$ \\
\hline POLITICAL RIGHTS & $\begin{array}{l}-21.8 \\
{[2.16]^{* *}}\end{array}$ & $\begin{array}{c}-21.2 \\
{[0.95]}\end{array}$ & $\begin{array}{c}-53.2 \\
{[1.25]}\end{array}$ & $\begin{array}{l}-43.9 \\
(1.99)^{* *}\end{array}$ & $\begin{array}{l}-43.6 \\
(1.00)\end{array}$ & $\begin{array}{l}-67.2 \\
(0.81)\end{array}$ \\
\hline FEDERAL & $\begin{array}{l}82.0 \\
{[1.56]}\end{array}$ & $\begin{array}{l}178.4 \\
{[1.86]^{*}}\end{array}$ & $\begin{array}{l}283 \\
{[1.62]}\end{array}$ & & & \\
\hline PSNS & $\begin{array}{c}-191.6 \\
{[2.23]^{* *}}\end{array}$ & $\begin{array}{l}-343.3 \\
{[1.88]^{*}}\end{array}$ & $\begin{array}{c}-703.5 \\
{[2.03]^{* *}}\end{array}$ & $\begin{array}{c}-403.6 \\
(2.42)^{* *}\end{array}$ & $\begin{array}{c}-762.0 \\
(2.31)^{* *}\end{array}$ & $\begin{array}{l}-1512.6 \\
(2.40)^{* *}\end{array}$ \\
\hline$R A I$ & & & & $\begin{array}{l}6.35 \\
(2.16)^{* *}\end{array}$ & $\begin{array}{l}10.3 \\
(1.78)^{*}\end{array}$ & $\begin{array}{l}16.5 \\
(1.49)\end{array}$ \\
\hline Maximum value for VIF & 2.67 & 3.36 & 5.23 & 2.89 & 2.88 & 2.89 \\
\hline Mean dependent variable & 148 & 373 & 832 & 217 & 545 & 1182 \\
\hline $\mathrm{R}^{2}$ & 0.393 & 0.425 & 0.453 & 0.413 & 0.312 & 0.343 \\
\hline White test ( $p$-value) & 0.0084 & 0.0001 & 0.0008 & 0.37 & 0.40 & 0.50 \\
\hline Number of countries & 113 & 113 & 113 & 68 & 68 & 68 \\
\hline
\end{tabular}

Huber-White robust $\mathrm{t}$-statistics in brackets and ordinary $\mathrm{t}$-statistics in parenthesis. ***, **, * indicates significant at $1 \%, 5 \%$ and $10 \%$ respectively

[1a] and [2a] Accumulated deaths up to September 30th 2020

[1b] and [2b] Accumulated deaths up to December 31st 2020

[1c] and [2c] Accumulated deaths up to June 30th 2021

Concerning our explanatory variables of interest, i.e. INSTITUTIONS, we start with POLITICAL RIGHTS, whose coefficient is negative and statistically significant only for estimates using accumulated data up to September 2020. Hence, the extent of political rights (or the kind of political regime meaning more/less democracy) could help combating the Covid-19 pandemic in the beginning of the pandemic, when countries had more difficulties and less knowledge and resources to deal with the pandemic, but it likely became less important over time.

Concerning decentralization, results are quite different. The coefficient on FED$E R A L$ is positive and marginally significant across specifications, thus implying a negative effect on the capacity of federal systems to deal with the pandemic vis-à-vis 
unitary countries. This is expected as federations are likely to have greater difficulties with national-subnational coordination. On the other hand, the results for the decentralization measure provided by the regional authority index (RAI) are more nuanced. Its effect is significant at 5\% level using data on accumulated deaths up to September 2020, at $10 \%$ at the end of 2020, and it is not significant using data for the whole analyzed period. Therefore, decentralization could have represented a minor detrimental factor in addressing the Covid-19 emergency but only in the beginning of the pandemic. Learning by doing over time to overcome coordination issues in decentralized settings could explain why any negative initial impact faded over time.

On the other hand, the coefficient on our measure of geographical political fragmentation, PSNS, is negative and statistically significant across all specifications and time periods: the higher the nationalization of the political party system in a country, the lower the number of Covid-19 deaths. Hence, the nationalization of party systems appears to be a key institutional feature to successfully addressing the pandemic. As hypothesized, countries with centralized political parties have been able to better coordinate national level policies leading to lower mortality rates from the Covid-19.

In summary, putting these results for the role of INSTITUTIONS all together, it emerges that the most relevant institutional feature leading to allowing for countries' good performance during the Covid-19 emergency is their form of political fractionalization as measured by political party integration or centralization, which does not only allow but also incentivizes policy coordination at the national level.

Regarding the control variables, previous country experience with respiratory diseases (IRD) does reduce the number of deaths due to the Covid-19. The effect of TOURISM, not surprisingly, changes over time. In line with Han et al. (2020), its coefficient is positive and highly significant to explain death tolls in 2020, but that effect fades away when the sample is extended to also include the first semester of 2021. Since tourism flows dramatically dropped with the pandemic, it became an irrelevant factor as time went on.

The coefficient on GDP capita is negative, as expected. But its statistical significance increases over time, from not significant in the first semester of 2020 to highly significant using data up to June 2021. Both the adaptation of resources to the pandemic and the vaccination process would explain this result. Richer countries have had more capacity to adapt their healthcare systems and to access vaccines once they were available (mostly in 2021).

The coefficient on AGE65 is positive and significant in estimates using data up to December 2020 and June 2021, confirming that aged populations face higher mortality risks. Surprisingly, the sign of the coefficient is negative in the estimates using data for the first period, up to the end of September 2020. This could be explained by a slower incidence of the pandemic for the elderly group in some countries/areas during the first wave of Covid-19, such as in some European countries with significantly aged populations (e.g., Bulgaria, Greece, Hungary, the Nordic countries). Those countries were not as severely hit as other countries (e.g., Italy, Spain, France, United Kingdom) and their individual cities (e.g., Milan, Madrid, Paris, and London), as also documented by Rodríguez-Pose and Burlina (2021). 
Contrary to our expectations, given for example the experience of Latin-American and other developing countries, the extent of the informal economy does not systematically affect the number of Covid-19 deaths as the coefficient on INFOR$M A L$ is consistently not statistically significant. Finally, as expected, a larger share of urban population (URBAN) worsens the effects of the pandemic by increasing the number of Covid-19 deaths. However, the statistical significance of this variable substantially drops in columns [2b] and [2c], for the periods covering up to December 2020 and up to June 2021, respectively. Thus, the role played by urbanization and, more generally, by density and agglomeration, was dampened by the geographical incidence and diffusion of Covid-19 over time, thus playing a significant role only in the timing of early outbreaks (see also Carozzi et al. 2020; Hamidi et al. 2020; Florida and Mellander 2021). ${ }^{9}$

\section{Conclusion}

The main goal of this paper has been to explain the extremely diverse performance across countries in containing the Covid-19 pandemic, as observed in recent times. Our approach relies on the economic theory of how coordination at the highest level is needed to address the presence of very large and pervasive negative externalities. Accordingly, once controlling for external or past and predetermined circumstances for each country (such as previous country experience with respiratory diseases), countries' performance depends critically on their institutional setup that may facilitate or, rather, hinder coordination for the necessary preventive policies to face and contain the pandemic.

Our main results, which are based on data for up to 113 countries around the world, show that democracies do not systematically perform worse than autocracies and that, within democracies, countries with a centralized political party system perform better than those with poorly nationalized politics. Although federal countries do appear to have had consistently greater difficulties than unitary countries, a finding that fits well with the role of coordination, overall, the role played by fiscal and administrative decentralization is not robust. However, further research efforts on this relationship are required before providing a definitive answer, especially on the potential role played by the level of decentralization of health systems. With the data available, we find that possible complementarity effects between fiscal and political institutions have not been significant in affecting the Covid-19 mortality. Overall,

\footnotetext{
${ }^{9}$ In addition to the control variables above we also considered two others: the level of health decentralization and climate. For the case of health decentralization data were lacking for a high number of countries in the sample, and when using the 54 observations available we obtained statistically insignificant results. Clearly, the potential role of health decentralization should be reexamined when more data become available. To control for climate differences, we used two variables: "hemisphere" and "latitude". For the first, the results were not statistically significant, with p-values between 0.22 and 0.80 . In the case of the second variable, "latitude," the estimated coefficient was statistically significant only when using data up to September 2021 and only for the southern hemisphere. At the end those variables were omitted to preserve degrees of freedom.
} 
the crucial role of the spatial fragmentation of politics in effectively addressing the pandemic is always confirmed in our estimations.

This research has been subject to some limitations, the most significant being data availability for many countries in important areas such as health decentralization. Our empirical analysis would need to be replicated once data for a longer period and more countries become available.

\section{Appendix}

List of countries included in the analysis (* means included in the sample for estimates with 68 observations).

Angola, Albania*, Argentina*, Armenia, Australia*, Austria*, Azerbaijan, Belgium*, Benin, Burkina Faso, Bangladesh, Bulgaria*, Bahrain, Bahamas, The*, Bosnia and Herzegovina*, Belarus, Belize*, Bolivia*, Brazil*, Barbados*, Bhutan, Botswana, Canada*, Switzerland*, Chile*, Cote d'Ivoire, Cameroon, Colombia*, Comoros, Cabo Verde, Costa Rica*, Croatia*, Cyprus*, Czech Republic*, Germany*, Denmark*, Dominican Republic*, Ecuador*, Spain*, Estonia*, Ethiopia, Finland*, France*, United Kingdom*, Georgia, Guinea, Guinea-Bissau, Greece*, Guatemala*, Honduras*, Hungary*, Indonesia*, India, Ireland*, Iran, Islamic Rep., Iceland*, Italy*, Jamaica*, Japan*, Kenya, Cambodia, Korea, Rep.*, Lebanon, St. Lucia, Sri Lanka, Lesotho, Lithuania*, Luxembourg*, Latvia*, Maldives, Mexico*, North Macedonia*, Malta*, Myanmar, Mongolia, Mozambique, Mauritius, Malawi, Malaysia*, Niger, Nigeria, Nicaragua*, Netherlands*, Norway*, Nepal, New Zealand*, Philippines*, Poland*, Portugal*, Paraguay*, Romania*, Russian Federation*, Senegal, Singapore*, Sierra Leone, El Salvador*, Suriname*, Slovak Republic*, Slovenia*, Sweden*, Togo, Thailand*, Trinidad and Tobago*, Turkey*, Tanzania, Uganda, Ukraine, Uruguay*, United States*, St. Vincent and the Grenadines, South Africa, Zambia, Zimbabwe.

Acknowledgements We thank the Editor and a reviewer for insightful suggestions and comments on the manuscript, and Alejandro Domínguez (GEN-UVigo) for his research assistance. A previous version of the paper circulated as GEN Working Paper A 2020-1 and as ICePP Working Paper 2018. This work was supported by the Spanish Ministry of Economy and Competitiveness (Grant number CSO2017-85024-C2-2-P).

\section{References}

Acemoglu D, Naidu S, Restrepo P, Robinson JA (2014) Democracy does cause growth. NBER Working Paper No. 20004

Bellemare MF, Masaki T, Pipinsky T (2017) Lagged explanatory variables and the estimation of causal effect. J Politics 79(3):949-963

Besley T, Coate S (2003) Centralized versus decentralized provision of local public goods: a political economy approach. J Public Econ 87:2611-2637

Carozzi F, Provenzano S, Roth S (2020) Urban Density and COVID-19. IZA Discussion Papers No. 13440

Channa A, Faguet JP (2016) Decentralization of health and education in developing countries: a qualityadjusted review of the empirical literature. World Bank Res Obs 31(2):199-241 
Coase RH (1960) The problem of social cost. J Law Econ 3:1-44

Dzau VJ, Balatbat C (2020) Strategy, coordinated implementation, and sustainable financing needed for COVID-19 innovations. Lancet 396:1469-1471

Elgin C, Oztunali O (2012) Shadow economies around the world: model based estimates. Technical report, Bogazici University Department of Economics

de Haan J, Siermann CLJ (1996) New evidence on the relationship between democracy and economic growth. Public Choice 86(1-2):175-198

Dur R, Roelfsema H (2005) Why does centralisation fail to internalise policy externalities? Public Choice 122(3):395-416

Ellingsen T (1998) Externalities vs internalities: a model of political integration. J Public Econ 68(2):251-268

Florida R, Mellander C (2021) The geography of COVID-19 in Sweden. The Annals of Regional Science $1-26$

González-Bustamante B (2021) Evolution and early government responses to COVID-19 in South America. World Dev 137:105180

Hale T, Petherick A, Phillips T, Webster S (2020) Variation in government responses to COVID-19. Blavatnik School of Government working paper n. 31

Hamidi S, Sabouri S, Ewing R (2020) Does density aggravate the COVID-19 pandemic? Early findings and lessons for planners. J Am Plann Assoc 86(2):495-509

Han E, Tan MMJ, Turk E, Sridhar D, Leung GM, Shibuya K, Asgari N, Oh J, García-Basteiro AL, Hanefeld J, Cook AR, Hsu LY, Teo YY, Heymann D, Clark H, McKee M, Legido-Quigley H (2020) Lessons learnt from easing COVID-19 restrictions: an analysis of countries and regions in Asia Pacific and Europe. Lancet 396:1525-1534

Hankla CR, Martinez-Vazquez J, Rodríguez RAP (2019) Local accountability and national coordination in fiscal federalism: a fine balance. Edward Elgar Publishing

Hooghe L, Marks G, Schakel AH, Osterkatz SC, Niedzwiecki S, Shair-Rosenfield S (2016) Measuring regional authority: a postfunctionalist theory of governance. Oxford University Press

Inman RP, Rubinfeld DL (1992) Fiscal federalism in Europe. Eur Econ Rev 46(65):4-660

Iverson T, Barbier EB (2020) National and Sub-National Social Distancing Responses to COVID-19. CESifo working paper n. 8452

Kashnitsky I, Aburto JM (2020) COVID-19 in unequally ageing European regions. World Dev 136:105170

Klibanoff P, Morduch J (1995) Decentralization, externalities, and efficiency. Rev Econ Stud 62(2):223-247

Lago-Peñas I, Lago-Peñas S (2009) Does the nationalization of party systems affect the composition of public spending? Econ Gov 10(1):85-98

Lago-Peñas I, Lago-Peñas S (2011) Decentralization and the nationalization of party systems. Eviron Plann C Gov Policy 29(2):244-263

Legido-Quigley H, Mateos-García JT, Campos VR, Gea-Sánchez M, Muntaner C, McKee M (2020) The resilience of the Spanish health system against the COVID-19 pandemic. Lancet Public Health 5(5): $251-\mathrm{e} 252$

Lin CYC (2010) How should standards be set and Met?: On the allocation of regulatory power in a federal system. BE J Econ Anal Policy 10(1):1-19

Martinez-Vazquez J, Lago-Penas S, Sacchi A (2017) The impact of fiscal decentralization: a survey. J Econ Surv 31(4):1095-1129

Oates W (1972) Fiscal federalism. Harcourt Brace Jovanovich, New York

Rodríguez-Pose A, Burlina C (2021) Institutions and the uneven geography of the first wave of the COVID-19 pandemic. J Reg Sci, forthcoming

Schellekens P, Sourrouille DM (2020) COVID-19 mortality in rich and poor Countries: a tale of two pandemics?. World Bank Policy Research working paper n. 9260

Snower DJ (2020) The Socio-Economics of Pandemics Policy (No. 8314). CESifo working paper n. 8314

Uchimura H, Jütting JP (2009) Fiscal decentralization, Chinese style: good for health outcomes? World Dev 37(12):1926-1934

Publisher's Note Springer Nature remains neutral with regard to jurisdictional claims in published maps and institutional affiliations. 